Note

\section{Effect of Dietary Paraquat on the Enzyme Activities Involved in Tryptophan-Niacin Metabolism in Rats}

\author{
Katsumi Shibata and Kazuo IwaI* \\ Department of Food Science and Nutrition, \\ Teikoku Women's University, Moriguchi, \\ Osaka 570, Japan \\ * Department of Food Science and Technology, \\ Faculty of Agriculture, Kyoto University, \\ Kyoto 606, Japan
}

Received January 28, 1988

Brown et al. ${ }^{1)}$ have reported that the intraperitoneal injection of paraquat (1,1'-dimethyl-4,4'-bipyridinium dichloride) to rats caused death and that nicotinic acid reduced the paraquat toxicity. They have suggested, but did not prove, that damage by paraquat is a consequence of the poisoning of quinolinate phosphoribosyltransferase (EC 2.4.2.19), ${ }^{\text {" }}$ similar to Escherichia coli poisoned by hyperbaric oxygen, ${ }^{2)}$ because it is considered that superoxide is a common intermediate in the mechanisms of toxicity for paraquat and hyperbaric oxygen. ${ }^{3)}$ Pearl ard Raffin $^{4)}$ have also reported that nicotinic acid reduced oxygen toxicity in mouse alveolar macrophages by providing an alternate pathway for NAD biosynthesis; they speculated that quinolinate phosphoribosyltransferase, which is the rate-limiting enzyme in tryptophan-NAD metabolism, ${ }^{5)}$ was rapidly inactivated in mouse alveolar macrophages exposed to hyperbaric oxygen.

In order to prove the effect of dietary paraquat on the activities of quinolinate phosphoribosyltransferase and some other enzymes involved in tryptophan-niacin metabolism in rats, this experiment was carried out.

Male rats of the Sprague Dawley strain was purchased from Clea Japan Inc., the rats being individually kept in wire-bottomed cages. The room temperature was $22 \pm 2^{\circ} \mathrm{C}$ and the humidity about $60 \%$, with a 06:00-18:00 (light) and 18:00-06:00 (dark) schedule.

The liver was removed from each rat under light ether anesthesia at around 9:00 a.m., and homogenized in 5volumes of cold $50 \mathrm{~mm}$ potassium phosphate buffer $(\mathrm{pH}$ 7.0) with a Yamato model LK-21 ultra-disperser. This homogenate was used for the determination of the protein and enzyme activities. Protein was measured by the method of Lowry et al. ${ }^{6)}$ with bovine serum albumin as the standard. The activities of kynureninase (EC 3.7.1.3), quinolinate phosphoribosyltransferase, NMN adenylyltransferase (EC 2.7.7.1), $\mathrm{NAD}^{+}$synthetase (EC 6.3.5.1) and nicotinamide methyltransferase (EC 2.1.1.1) were measured by the methods of Takeuchi et al., ${ }^{73}$ Iwai and Taguchi, ${ }^{8)}$ Kurokawa et al.,9) $\mathrm{Yu}$ and Dietrich ${ }^{10}$ and Cantoni, ${ }^{11)}$ respectively.

Weanling male rats of the Sprague Dawley strain (3 weeks old) were fed ad libitum with a nicotinic acid-free, $20 \%$ casein diet $(20 \%$ vitamin-free milk casein, $46 \% \%$ cornstarch, $23 \%$ sucrose, $5 \%$ corn oil, $0.1 \%$ choline- $\mathrm{Cl}$, $5 \%$ Harper's salt mixture, ${ }^{12)} 1 \%$ nicotinic acid-free Harper's vitamin mixture, ${ }^{12)} 1 \mathrm{mg} / 100 \mathrm{~g}$ of diet retinol palmitate, $3.75 \mu \mathrm{g} / 100 \mathrm{~g}$ of diet ergocalciferol and $0.6 \mathrm{mg} /$ $100 \mathrm{~g}$ of diet $d l-\alpha$-tocopherol) with or without $0.05 \%$ paraquat. At the 8 th day, the rats were killed, and the livers were removed. The key enzyme activities for tryptophan-niacin metabolism were measured. As shown in Table I, the activity of quinolinate phosphoribosyltransferase was proved to decrease to about $60 \%$ by feeding the paraquat-containing diet, compared with that of the control, which is consistent with the speculation of Brown et al. ${ }^{1)}$ Furthermore, the activities of kynureninase, NMN adenylyltransferase and $\mathrm{NAD}^{+}$synthetase also decreased to about $25 \%, 62 \%$ and $21 \%$, respectively, by the administration of the paraquat-containing diet. However, the activity of nicotinamide methyltransferase was not affected. From these findings, dietary paraquat was found to reduce the conversion ratio from tryptophan to NAD because the kynureninase activity was reduced to $25 \%$ and quinolinate phosphoribosyltransferase activity to $60 \%$. The biosynthetic activity of NAD from nicotinic acid and nicotinamide was also found to be reduced by paraquat administration. Therefore, the niacin requirement would be increased when paraquat is taken. For the biosynthesis of NAD from nicotinic acid and tryptophan, NAD ${ }^{+}$ synthetase is involved as well as NMN adenylyltransferase. On the other hand, for the biosynthesis of NAD from nicotinamide, NMN adenylyltransferase is involved but not $\mathrm{NAD}^{+}$synthetase. Accordingly, the reduction of the biosynthetic activity of NAD from nicotinic acid and tryptophan could be severer than that from nicotinamide because the NMN adenylyltransferase activity was reduced to $62 \%$ by paraquat and $\mathrm{NAD}^{+}$synthetase activity to $21 \%$. It has been reported that the NAD biosynthetic pathway from nicotinic acid and quinolinic acid mainly exists only in liver, and that from nicotinamide exists in all the tissues. ${ }^{13)}$ Brown et al. ${ }^{1)}$ showed that the levels of liver NAD and niacin in paraquat-injected rats was signifcantly reduced compared to normal rats, and that when a large amount of nicotinic acid simultaneously with paraquat was injected, the levels of liver NAD and niacin remained in the normal range. Accordingly, it is possible that the administration of nicotinamide reduces the paraquat toxicity more than the administration of nicotinic acid, although the administration of nicotinic acid has been reported to reduce paraquat toxicity ${ }^{1 /}$ and hyperbaric oxygen toxicity. ${ }^{4}$ 
Table I. Effect of Dietary Paraquat on the Enzyme Activities Involved in TRYPTOPHAN-Niacin METABOLISM

\begin{tabular}{|c|c|c|c|}
\hline & & Control & Paraquat* \\
\hline \multirow[t]{2}{*}{ Kynureninase } & (nmol/hr/g of liver) & $\begin{array}{c}234.8 \pm 23.8^{2} \\
(100 \%)\end{array}$ & $\frac{60.3 \pm 21.2^{b}}{(26 \%)}$ \\
\hline & (nmol/hr/mg of protein) & $\begin{array}{c}1.36 \pm 0.15^{\mathrm{a}} \\
(100 \%)\end{array}$ & $\begin{array}{c}0.38 \pm 0.03^{b} \\
(28 \%)\end{array}$ \\
\hline \multirow[t]{2}{*}{ QPRTase $^{1}$} & (nmol/hr/g of liver) & $\begin{array}{c}340.1 \pm 54.2^{\mathrm{a}} \\
(100 \%)\end{array}$ & $\begin{array}{c}198.4 \pm 114.3^{\mathrm{b}} \\
(58 \%)\end{array}$ \\
\hline & (nmol/hr/mg of protein) & $\begin{array}{l}1.98 \pm 0.36^{\mathrm{a}} \\
(100 \%)\end{array}$ & $\begin{array}{c}1.18 \pm 0.35^{b} \\
(60 \%)\end{array}$ \\
\hline \multirow[t]{2}{*}{ NMN ATase ${ }^{2}$} & (nmol/hr/g of liver) & $\begin{array}{c}6653.6 \pm 644.4^{\mathrm{a}} \\
(100 \%)\end{array}$ & $\begin{array}{c}4057.9 \pm 2117.4^{b} \\
(61 \%)\end{array}$ \\
\hline & (nmol/hr/mg of protein) & $\begin{array}{c}38.58 \pm 2.78^{a} \\
(100 \%)\end{array}$ & $\underbrace{24.44 \pm}_{(63 \%)} 5.44^{\mathrm{b}}$ \\
\hline \multirow[t]{2}{*}{$\begin{array}{l}\mathrm{NAD}^{+} \\
\text {synthetase }\end{array}$} & (nmol/hr/g of liver) & $\begin{array}{c}457.9 \pm 149.3^{\mathrm{a}} \\
(100 \%)\end{array}$ & $\begin{array}{c}104.0 \pm 100.7^{b} \\
(23 \%)\end{array}$ \\
\hline & (nmol/hr/mg of protein) & $\begin{array}{c}2.65 \pm 0.82^{a} \\
(100 \%)\end{array}$ & $\begin{array}{c}0.55 \pm 0.50^{\mathrm{b}} \\
(21 \%)\end{array}$ \\
\hline \multirow[t]{2}{*}{ NMTase $^{3}$} & (nmol/hr/g of liver) & $\begin{array}{c}446.6 \pm 84.1 \\
(100 \%)\end{array}$ & $\begin{array}{c}495.4 \pm 184.0 \\
(111 \%)\end{array}$ \\
\hline & (nmol/hr/mg of protein) & $\begin{array}{c}2.60 \pm 0.51 \\
(100 \%)\end{array}$ & $\begin{array}{l}3.08 \pm 0.38 \\
(119 \%)\end{array}$ \\
\hline
\end{tabular}

Values are means \pm S.D. for 5 rats (control) and 3 rats (paraquat); means in the same line not sharing a common superscript differ significantly at $p<0.05$.

The significance of differences between means having the same variance and the different variance analyses by an $F$-test were evaluated by Student's $t$ test and Welch's test, respectively.

1 QPRTase = quinolinate phosphoribosyltransferase.

$2 \quad \mathrm{NMN}$ ATase $=\mathrm{NMN}$ adenylyltransferase.

$3 \quad$ NMTase $=$ nicotinamide methyltransferase.

* In the paraquat group, two rats died on the 7 th day.

\section{REFERENCES}

1) O. R. Brown, M. Heitkamo and C.-S. Song, Science, 212, 1510 (1981).

2) O. R. Brown, F. Yein, D. Boehme, L. Foudin and C.S. Song, Biochem. Biophys. Res. Commun., 91, 982 (1972).

3) Y. Koyabashi, S. Okahata and T. Usui, Biochem. Biophys. Res. Commun., 91, 1288 (1979).

4) R. G. Pearl and T. A. Raffin, Pharmacology, 27, 219 (1983).

5) U. Satyanarayana and B. S. Narasinga Rao, J. Nutr., 107, 2213 (1977).
6) O. H. Lowry, N. J. Rosebrough, A. L. Farr and R. J. Randall, J. Biol. Chem., 193, 265 (1951).

7) F. Takeuchi, H. Otsuka and Y. Shibata, J. Biochem., 88, 987 (1980).

8) K. Iwai and H. Taguchi, J. Nutr. Sci. Vitaminol., 19, 491 (1973).

9) M. Kurokawa, T. Kato and H. Inamura, Proc. Jpn. Acad., 42, 1217 (1966).

10) C. K. Yu and L. S. Dietrich, J. Biol. Chem., 247, 4794 (1972).

II) G. L. Cantoni, J. Biol. Chem., 189, 203 (1951).

12) A. E. Harper, J. Nutr., 68, 405 (1959).

13) K. Shibata, T. Hayakawa and K. Iwai, Agric. Biol. Chem., 50, 3037 (1986). 